\title{
Memory and language impairments are associated with anxiety disorder severity in childhood
}

\author{
Juliana B. Sbicigo, ${ }^{1}$ (D) Rudineia Toazza, ${ }^{2}$ (D) Natália Becker, ${ }^{1}$ (D) Kimberly Ecker, ${ }^{2}$ (D) \\ Gisele G. Manfro, ${ }^{2}$ Jerusa F. de Salles ${ }^{1}$ D
}

\begin{abstract}
Introduction: Children with anxiety disorders have been suggested to possess deficits in verbal fluency, shifting and attention, with inconsistent results regarding working memory and its subcomponents. This study extends previous findings by analyzing the performance of children with anxiety disorders in a wide range of neuropsychological functions.

Methods: We evaluated 54 children with a primary diagnosis of an anxiety disorder according to diagnostic criteria from the Diagnostic and Statistical Manual of Mental Disorders, 5th edition (DSM-5) using subtests of a neuropsychological battery. The severity of anxiety disorders was assessed using the Pediatric Anxiety Rating Scale (PARS). We calculated the frequency of neuropsychological impairments ( -1.5 standard deviation of the normative sample). Comparisons between groups were performed based on the severity of anxiety symptoms, as well as in the presence of one vs. more diagnoses of anxiety disorder.

Results: We found higher impairment in visuospatial working memory (23.1\%), semantic memory $(27.8 \%)$, oral language $(35.4 \%)$ and word writing $(44.4 \%)$ in anxious children. Moreover, children with higher anxiety severity presented lower performance in visuospatial working memory, inferential processing, word reading, writing comprehension, copied writing, and semantic verbal fluency $(\mathrm{d}=0.49$ to 0.96 [Cohen's d]). The higher the number of anxiety diagnoses, the lower the performance in episodic memory and oral and written language ( $d=0.56$ to 0.77 ).

Conclusion: Our data suggested the presence of memory (visuospatial working memory and semantic memory) and language deficits (oral and writing) in some children with an anxiety disorder. Severity and number of anxiety diagnoses were associated with lower performance in memory and language domains in childhood.
\end{abstract}

Keywords: Anxiety disorders, neuropsychology, memory, language, child.

\section{Introduction}

Pediatric anxiety disorders are among the most common mental disorders in Brazil. In 2015, one study reported that between 4.2 and $9.4 \%$ of the children of four Brazilian regions were affected by these disorders. ${ }^{1}$
The conditions often have a chronic course and are frequently associated with considerable impairment and dysfunction. ${ }^{2}$ Anxiety disorders usually have their onset during childhood and adolescence, and clinical presentation may range from transient mild symptoms to full-blown anxiety disorders. ${ }^{2}$ Understanding the

\footnotetext{
${ }^{1}$ Núcleo de Estudos em Neuropsicologia Cognitiva (NEUROCOG), Departamento de Psicologia do Desenvolvimento e da Personalidade, Instituto de Psicologia, Universidade Federal do Rio Grande do Sul (UFRGS), Porto Alegre, RS, Brazil. ${ }^{2}$ Programa de Transtornos de Ansiedade na Infância e Adolescência, (PROTAIA), Hospital de Clínicas de Porto Alegre (HCPA), UFRGS, Porto Alegre, RS, Brazil.

Submitted Jun 18 2019, accepted for publication Nov 042019.

Suggested citation: Sbicigo JB, Toazza R, Becker N, Ecker K, Manfro GG, Salles JF. Memory and language impairments are associated with anxiety disorder severity in childhood. Trends Psychiatry Psychother. 2020;42(2):161-170. http://dx.doi.org/10.1590/2237-6089-2019-0051
} 
neuropsychological performance underlying the severity of anxiety disorders might ultimately improve our knowledge of etiological mechanisms and treatment strategies.

Most of the research on anxiety disorders has investigated the role of anxious symptoms on cognitive functions like attention and executive functions. ${ }^{3,4}$ According to some authors, attention can be interpreted as being divided into three main dissociable networks: 1 ) executive attention (ability to solve and monitor conflicts in process competing for stimuli and responses); 2) alerting (controlling keenness to respond to novel stimuli); and 3) orienting attention that sets up sensory information. ${ }^{5}$ Attention orienting towards threats has been one of the most replicable results for anxiety disorders. In addition to the role of symptoms in attention orienting, positive results have also been found for deficits in some executive function components, such as phonemic verbal fluency, ${ }^{6,7}$ executive attention, ${ }^{8}$ and working memory. ${ }^{9-11}$ Comprehensive investigations of distinct aspects of memory (i.e., semantic and episodic verbal memory) and language (i.e., oral and written) are scarce, with some exceptions. ${ }^{12,13}$ It is also known that most researches did not evaluate the role of severity when investigating neuropsychological impairments in children with anxiety disorders. Some studies have shown, for example, that severity is very important when investigating the role of threat bias in anxiety disorders, as well as when investigating deficits in distinct aspects of memory. ${ }^{13,14}$

Neuropsychological studies have described cognitive dysfunctions in children and adolescents with anxiety disorders, but their results are inconsistent. In a study evaluating attention, verbal episodic memory, working memory, visuoconstructive skills, and executive functions, no differences were found in patients with anxiety disorders as compared to a non-anxious control group, except for the digit span backward task. ${ }^{12}$ Furthermore, the group with mild anxiety disorder presented higher performance than the control group in this task. ${ }^{12}$ Another study, using the same community sample, showed that youths with anxiety had higher deficits in verbal fluency when compared with the non-anxious group. ${ }^{6}$ This finding was replicated and extended through young children, showing that verbal fluency is consistently associated with severity of anxiety disorders, regardless of the presence of attention-deficit/hyperactivity disorder (ADHD) symptoms. ${ }^{7}$

Poor working memory performance is one of the neuropsychological functions most frequently associated with pediatric anxiety disorders. ${ }^{9,10}$ Working memory is usually described as a framework for a series of interactive processes that comprise temporary storage and the manipulation of information. ${ }^{15}$ According to Baddeley et al., ${ }^{15,16}$ the working memory model can be understood as comprising three components: 1) a phonological loop, responsible for storing and maintaining phonological information; 2) a visuospatial sketchpad, which stores and maintains visual and spatial information; and 3) a central executive, which has a general storage capacity and is responsible for the manipulation of temporary information. A fourth component, the episodic buffer - a multidimensional storage system that integrates information from the long-term memory, the slave systems, and perception ${ }^{17}$ - has not been investigated directly in the studies.

Some other studies have suggested worse spatial working memory and span performance in children with anxiety than in healthy control children. ${ }^{13,18}$ A study that evaluated the association between anxiety trait and academic performance found that this association was significantly mediated by verbal working memory, but not by spatial working memory. ${ }^{19}$ It was also found that anxious children did not differ from normal controls with regard to performance in attentional and verbal memory functions. ${ }^{14,20}$ Moreover, Hadwin et al. ${ }^{14}$ found no differences between high and low state anxiety groups in working memory tasks (visuospatial and phonological and central executive). The inconsistent results could be due to the presence of children with different anxiety disorders in the sample, as well as to the wide age range and variable intelligence quotient (IQ) of the children. ${ }^{20}$

Anxiety disorders in children and adolescents are also associated with low language skills and low shifting performance, possibly mediated by decreased attention, decreased short-term memory or working memory. ${ }^{11}$ However, the study of Toren et al. ${ }^{11}$ did not find an association between anxiety and nonverbal processes. Another study, while investigating a non-clinical sample of children, found an association between low levels of attention and inhibitory control and high levels of anxiety. ${ }^{21}$ Impaired executive attention in children was also associated with anxiety disorders and with high levels of anxiety symptoms in another non-clinical sample. ${ }^{8}$

Considering these findings, there is some evidence that anxiety in children is associated with deficits in verbal fluency, ${ }^{7}$ shifting and attention, ${ }^{11,21}$ but data are inconsistent regarding working memory and its subcomponents. ${ }^{14,18}$ Thus, further research is needed to extend the incipient and controversial literature available on the neuropsychological profiles of children with anxiety disorders. Understanding the relationship 
between cognitive performance and anxiety symptoms is important both for the development of specific psychological, psychiatric and pharmacological interventions and for monitoring different trajectories and outcomes of anxiety disorders in children.

Therefore, the primary aim of this study was to assess the neuropsychological performance of children with a diagnosis of anxiety disorder in memory (semantic, verbal episodic and working memory), attention (visual and auditory), language (oral and written) and executive functions (verbal fluency and inhibitory control), compared with the normative sample of the instrument. A second objective was to compare the neuropsychological performance of children according to symptom severity and the presence of one vs. multiple diagnoses of anxiety disorders. Based on the literature, we hypothesized that children with anxiety disorders would have lower performance on working memory, language, and verbal fluency, and that these neuropsychological functions would be more affected in children with greater symptom severity and with the presence of two or more different anxiety disorders.

\section{Method}

\section{Participants}

Our sample comprised 54 children from a community sample (50\% girls), aged between 6 and 12 years $($ mean $=8.94$, standard deviation $[S D]=1.69)$, with a mean of $2.70(S D=1.69)$ years of education and a primary diagnosis of anxiety disorder, who were willing to participate in a randomized clinical trial for psychological treatment. ${ }^{22}$ Participants were recruited via mass media advertising that asked for children who had difficulty/fear of being separated from parents or liaison figures; excessive concern with everything; or excessive shyness) and were first screened by a telephone interview. After the telephone interview, potentially eligible children and their parents or caregivers were invited to undergo a structured clinical interview with trained psychiatrists and psychologists in order to assess diagnostic criteria.

We included in this study children with a diagnosis of generalized anxiety disorder (GAD; $\mathrm{n}=41$, $75.9 \%$ ), separation anxiety disorder (SeAD; $n=45$, $83.3 \%$ ) and/or social anxiety disorder (SoAD; $n=17$, $31.5 \%)$. From the total sample, $31.5 \%$ of the children presented only one anxiety disorder, while $46.3 \%$ and $22.2 \%$ presented two and three diagnoses of anxiety disorders, respectively.

Participants presenting with other psychiatric disorders judged by the clinician to cause more impairment or distress than GAD, SeAD or SoAD (e.g., developmental disorder, ADHD, challenging oppositional disorder, conduct disorder or obsessivecompulsive disorder) were excluded. We also excluded: participants who had received previous psychiatric treatment, i.e., lifetime history of any type of psychotherapy or psychiatric medication; and those with intellectual disability, defined as a score below the 5th percentile on Raven's Progressive Matrices assessment. ${ }^{23,24}$

\section{Ethical approval}

This study was approved by the ethics committee of Hospital de Clínicas de Porto Alegre (protocol 12-0254) and followed national and international guidelines for research involving humans, according to the Resolution 510/2016 from the Brazilian National Health Council (Conselho Nacional de Saúde [CNS]). All parents or guardians signed an informed consent form before entering the study.

\section{Psychiatric diagnosis}

All children underwent a comprehensive psychiatric diagnostic evaluation using the Schedule for Affective Disorders and Schizophrenia for School-Age Children - Present and Lifetime (K-SADS-PL) ${ }^{25}$ administered by doctoral- or master-degree level clinicians and weekly supervised by a senior clinician. The K-SADS-PL is a semi-structured interview used to diagnose childhood psychiatric disorders based on criteria from the Diagnostic and Statistical Manual of Mental Disorders, 4th edition (DSM-IV). ${ }^{26}$ We adapted some of the questions to reflect changes made in the DSM-5. The K-SADS-PL has been adapted to Brazilian Portuguese and presented good psychometric properties. ${ }^{27}$

\section{Disorder severity rating}

Pediatric Anxiety Rating Scale (PARS)

The PARS is a clinician-rated measurement of anxiety severity. This instrument rates anxiety severity, frequency, distress, avoidance, and interference in daily functioning, in accordance with standardized methods. ${ }^{28}$ We used the scores on the 50 symptoms evaluated as present/absent, varying from 0 to 50 . Studies using the PARS in a Brazilian population have demonstrated satisfactory reliability of this scale. ${ }^{28}$

\section{Neuropsychological domains}

Brazilian Brief Neuropsychological Assessment Battery (NEUPSILIN-Inf)

We evaluated neuropsychological dimensions using the NEUPSILIN-Inf. ${ }^{29-31}$ Psychologists and speech therapists with formal training in neuropsychology 
performed the evaluations. This instrument is a brief neuropsychological screening instrument developed to evaluate eight cognitive abilities: temporal and spatial orientation, attention, visual perception, arithmetic skills, oral and written language, verbal and visual memory, praxis, and executive functions (verbal fluency and problem solving). In the present study, the following subtests were applied: attention, memory, language and executive functions (Box 1). The test provides a brief neuropsychological profile of each cognitive function and its preserved and deficient aspects through quantitative and qualitative scores. We used the normative test group to control for age and type of school.

This measure has been developed specifically for the Brazilian population, therefore it is culturally appropriate for this sample, assuming that language and culture markedly influence neuropsychological performance. ${ }^{29,31}$ Also, Brazilian studies have demonstrated the validity and reliability of this battery. ${ }^{29,31}$ Psychologists and psychology students with training in neuropsychology performed this evaluation.

\section{Intelligence quotient}

IQ was assessed using Raven's Progressive Matrices, ${ }^{21,23}$ a nonverbal IQ test designed to assess intellectual level in 5- to 11-year-old children.

\section{Statistical analysis}

First, we presented the frequency of children with a $z$-score $<1.5 \mathrm{SD}$ in comparison with the Brazilian normative sample of the NEUPSILIN-Inf battery by age. $^{31}$ This cut-off selected approximately $5 \%$ of children with lower performance as compared to the reference sample. The data were not normally distributed. Second, we categorized the sample into low and high severity based on the median PARS score and compared the scores obtained on each neuropsychological test. Afterwards, we established two groups of children: a) children presenting only one anxiety disorder diagnosis; and b) children with two or more comorbid anxiety disorder diagnoses. Differences between groups by severity (low vs. high severity) and by number of anxiety disorders (one vs. two or more) were performed using Mann-Whitney's $U$ test. To deal with alpha inflation due to multiple comparisons, the false discovery correction rate was applied (FDT). ${ }^{32}$ We used the equation $r=z / \sqrt{ } N$ to calculate the effect size of the differences between groups. ${ }^{33}$ In the formula, $z$ is the $\mathrm{z}$ distribution and $\mathrm{N}$ is the study sample size. In order to compare the calculated effect size with other effect sizes (for example Cohen's d), the following formula was used: $d=2 r / \sqrt{ }(1-r 2) \cdot{ }^{33}$ Effect sizes were classified as small (0.2), moderate (0.5) and large $(0.8)$, according to Cohen's guidelines. ${ }^{34}$ We adopted a $5 \%$ chance of significance. All analyses were performed using the Statistical Package for the Social Sciences (SPSS) version 24.0.

\section{Results}

Table 1 shows the frequency of children diagnosed with anxiety disorder scoring below the mean $(z<1.5$ $\mathrm{SD}$ of the normative sample) in the cognitive domains of the neuropsychological battery. Children had difficulties in memory (visuospatial working memory and semantic memory) and oral and written language subtests. In the word writing subtest, about 44\% (24 children) presented impaired performance.

Our data showed statistically different scores in working memory and oral language according to severity of the anxiety disorder in our sample. More specifically, Table 2 shows that, when compared to children with low anxiety severity, children with high severity had lower medians in visuospatial working memory, oral language (comprehension and processing of inferences), written language (word reading, comprehension, spontaneous writing and copied writing) and semantic verbal fluency. In this latter function, the difference reached a large effect size $(d=0.96)$.

Table 3 shows the neuropsychological subtests in which there were statistically significant differences between the groups according to number of anxiety disorders. Children with two or three comorbid diagnoses of anxiety disorders performed poorly in six domains as compared to the group with only one diagnosis of anxiety disorder, with moderate effect sizes. There were no significant differences in the other neuropsychological subtests (Table S1, available as online-only supplementary material). 
Box 1 - List of the domains and tasks of the Brazilian Brief Neuropsychological Assessment Battery (NEUPSILIN-Inf) used in this study

\begin{tabular}{|c|c|c|}
\hline Domains & Tas & ks and subtests \\
\hline Attention & 1) & $\begin{array}{l}\text { Visual attention: Image cancellation - Requires focused attention on visual mode and ability of inhibition. } \\
\text { The final score is the number of targets correctly canceled. }\end{array}$ \\
\hline & 2) & $\begin{array}{l}\text { Auditory attention: Digit span forward - Children are told a sequence of digits ( } 2 \text { to } 5 \text { items) and they } \\
\text { have to repeat them in the exact same order. }\end{array}$ \\
\hline Memory & Wo & rking memory \\
\hline & Pho & nological and central executive: \\
\hline & 1) & $\begin{array}{l}\text { Digit span backward - Children are told a sequence of digits ( } 2 \text { to } 5 \text { items) and they have to repeat them in } \\
\text { the inverse order. }\end{array}$ \\
\hline & 2) & $\begin{array}{l}\text { Pseudoword span - Children are told a sequence of pseudowords and they have to repeat them. The number } \\
\text { of stimuli progressively increases from } 1 \text { to } 4 \text { items. }\end{array}$ \\
\hline & Visı & uospatial operational: \\
\hline & 3) & $\begin{array}{l}\text { Working memory (operational) visuospatial in the reverse order - The examiner points out progressively } \\
\text { longer sequences of stimuli (i.e., squares that were randomly arranged on a blank sheet), and the child is } \\
\text { asked to repeat pointing out the stimuli in the inverted presentation order immediately after the model was } \\
\text { presented by the examiner. }\end{array}$ \\
\hline & Ver & bal and visual episodic-semantic memory \\
\hline & 4) & Immediate and late recall (words) - Consists of the oral recall of 9 words. \\
\hline & 5) & Immediate recall (pictures) - Consists of the oral recall of 9 pictures. \\
\hline & 6) & Semantic memory - Consists of 4 questions that access the child's prior knowledge (long-term memory). \\
\hline Language & Ora & l language \\
\hline & 1) & Nomination - Picture naming (9 pictures). \\
\hline & Pho & nological awareness: \\
\hline & 2) & $\begin{array}{l}\text { Rhyme - Children are presented with } 3 \text { words that are named by the examiner. Children are asked to } \\
\text { identify the } 2 \text { of them that rhyme (or that "are sounding the same"). The task consists of } 2 \text { practice items } \\
\text { and } 4 \text { test trials (maximum score: } 4 \text { points). }\end{array}$ \\
\hline & 3) & $\begin{array}{l}\text { Phonemic subtraction task - Requires the participants to omit the initial phoneme (or the final phoneme) } \\
\text { from a nonword. Children are presented a short nonword orally and asked to state the nonword without the } \\
\text { first (or last) sound. }\end{array}$ \\
\hline & Ora & I comprehension: \\
\hline & & $\begin{array}{l}\text { Oral comprehension - Words and phrases are presented orally. Children should point to the drawing } \\
\text { corresponding to what is being said. There are } 3 \text { options to choose: } 1 \text { correct and } 2 \text { distracting. }\end{array}$ \\
\hline & Infe & erential processing: \\
\hline & 5) & $\begin{array}{l}\text { Processing of inferences - Metaphors and proverbs are presented orally. Children should explain their } \\
\text { meaning. }\end{array}$ \\
\hline & Wri & itten language \\
\hline & 6) & $\begin{array}{l}\text { Reading aloud syllables, words, and pseudowords - The stimuli are } 6 \text { syllables, } 6 \text { real words (regular and } \\
\text { irregular; frequent and infrequent; short and long) and } 5 \text { pseudowords. }\end{array}$ \\
\hline & 7) & $\begin{array}{l}\text { Writing comprehension - Five words and phrases are presented one by one in writing. The child should read } \\
\text { silently and then point at the target figure. Two distractors are presented for each word or phrase. }\end{array}$ \\
\hline & 8) & $\begin{array}{l}\text { Writing words and pseudowords - Stimuli are dictated by the examiner, one at a time. Only after the end of } \\
\text { the word/nonword can the child start writing. Words are dictated in the usual pronunciation of the region. } \\
\text { The stimuli are } 14 \text { real words (with } 4 \text { monosyllables) and } 5 \text { pseudowords. }\end{array}$ \\
\hline & & Spontaneous writing - Involves writing a complete sentence. \\
\hline & 10) & Writing copied - Involves copying a complete sentence. \\
\hline Executive & 1) & Semantic verbal fluency - Children are asked to say animal names in 1 minute. \\
\hline functions & 2) & $\begin{array}{l}\text { Inhibitory control - By the auditory go/no go task, in which } 0 \text { to } 9 \text { digits are presented to the child at a } \\
\text { rate of } 1 \text { item per second, and the child has to respond "yes" each time the child listens to one digit, except } \\
\text { for the digit } 8 \text {, for which the child should remain silent. }\end{array}$ \\
\hline
\end{tabular}

For more details about the test, description and rating of the tasks, see Salles et al. ${ }^{30}$ 
Table 1 - Median and frequency (\%) of children with impairments in neuropsychological subtests

\begin{tabular}{|c|c|c|c|c|c|}
\hline Subtest (z scores) & $\mathbf{N}$ & Md & Min & Max & $f(\%)$ \\
\hline \multicolumn{6}{|l|}{ Visual attention } \\
\hline Image cancellation & 54 & 0.10 & -6.85 & 1.19 & $7(13)$ \\
\hline \multicolumn{6}{|l|}{ Auditory attention } \\
\hline Digit span forward & 54 & 0.49 & -5.06 & 2.03 & $5(9.3)$ \\
\hline Attention - Total & 54 & 0.59 & -8.18 & 3.00 & $6(11.1)$ \\
\hline \multicolumn{6}{|l|}{ Working memory } \\
\hline Digit span backward & 49 & -0.27 & -3.95 & 1.61 & $11(22.4)$ \\
\hline Pseudoword span & 48 & -0.06 & -2.86 & 2.47 & $3(5.8)$ \\
\hline Phonological and central executive & 52 & -0.41 & -3.98 & 2.35 & $9(18.8)$ \\
\hline Visual span backward & 52 & -0.02 & -4.49 & 2.02 & $12(23.1)$ \\
\hline Total & 48 & -0.22 & -4.17 & 1.67 & $11(23.4)$ \\
\hline \multicolumn{6}{|l|}{ Episodic memory } \\
\hline Immediate recall (words) & 54 & -0.21 & -2.85 & 1.84 & $9(16.7)$ \\
\hline Late recall (words) & 54 & -0.48 & -3.44 & 1.85 & $8(14.8)$ \\
\hline Immediate recall (pictures) & 54 & -0.65 & -5.23 & 3.18 & $9(16.7)$ \\
\hline Semantic memory & 54 & 0.25 & -5.70 & 1.18 & $15(27.8)$ \\
\hline Episodic-semantic memory - Total & 54 & 0.47 & $-2,55$ & 5.62 & $10(18.5)$ \\
\hline \multicolumn{6}{|l|}{ Oral language } \\
\hline Naming & 49 & 0.28 & -7.92 & 0.46 & $4(8.2)$ \\
\hline Phonological awareness (rhyme) & 53 & 0.33 & -3.70 & 0.88 & $13(24.5)$ \\
\hline Phonemic subtraction & 54 & 0.48 & -9.66 & 0.87 & $8(14.8)$ \\
\hline Phonological awareness - Total & 53 & 0.21 & -9.50 & 1.06 & $8(15.1)$ \\
\hline Comprehension & 54 & 0.31 & -3.72 & 0.62 & $9(16.7)$ \\
\hline Inferential processing & 54 & -0.72 & -4.00 & 1.82 & $15(27.8)$ \\
\hline Total & 48 & -0.88 & -4.06 & 1.95 & $17(35.4)$ \\
\hline \multicolumn{6}{|l|}{ Written language } \\
\hline Syllable reading & 53 & 0.28 & -3.94 & 0.52 & $6(11.3)$ \\
\hline Word reading & 54 & 0.17 & -10.94 & 0.77 & $12(22.2)$ \\
\hline Pseudoword reading & 54 & 0.94 & -4.82 & 1.22 & $11(20.4)$ \\
\hline Reading - Total & 53 & 0.36 & -5.75 & 1.19 & $10(18.9)$ \\
\hline Comprehension & 54 & 0.16 & -6.17 & 0.45 & $9(16.7)$ \\
\hline Words & 54 & -0.73 & -9.47 & 1.63 & $24(44.4)$ \\
\hline Pseudowords & 54 & 0.36 & -5.84 & 0.84 & $13(24.1)$ \\
\hline Words and pseudowords - Total & 54 & -0.82 & -10.0 & -1.11 & $22(41.0)$ \\
\hline Spontaneous writing & 54 & 0.36 & -2.46 & 1.14 & $13(24.1)$ \\
\hline Copied writing & 54 & 0.16 & -5.31 & 0.81 & 9 (16.7) \\
\hline Total & 53 & -0.44 & -8.43 & 1.50 & $14(26.4)$ \\
\hline \multicolumn{6}{|l|}{ Executive functions } \\
\hline Semantic verbal fluency & 51 & -0.43 & -1.99 & 9.13 & $3(5.9)$ \\
\hline Go/no go & 54 & 0.16 & -5.59 & 1.83 & $7(13)$ \\
\hline
\end{tabular}

$\mathrm{f}=$ frequency $; \mathrm{Md}=$ median; $\mathrm{Max}=$ maximum; Min = minimum; $\mathrm{N}=$ number of subjects. 
Table 2 - Neuropsychological performance (z scores) according to anxiety severity

\begin{tabular}{|c|c|c|c|c|c|c|}
\hline Subtest (z scores) & $\mathbf{n}$ & Low severity & $\mathbf{n}$ & High severity & $\mathbf{U}$ & d \\
\hline \multicolumn{7}{|l|}{ Visual attention } \\
\hline Image cancellation & 29 & 0.13 & 24 & 0.05 & 327.50 & - \\
\hline \multicolumn{7}{|l|}{ Auditory attention } \\
\hline Digit span forward & 29 & 0.85 & 24 & 0.44 & 296.50 & - \\
\hline Attention - Total & 29 & 0.74 & 24 & 0.12 & 274.00 & - \\
\hline \multicolumn{7}{|l|}{ Working memory } \\
\hline Digit span backward & 28 & -0.25 & 20 & -0.26 & 253.50 & - \\
\hline Pseudoword span & 29 & 0.08 & 22 & -0.06 & 300.50 & - \\
\hline Phonological and central executive & 28 & -0.29 & 19 & -0.37 & 301.50 & - \\
\hline Visual span backward & 28 & 0.12 & 23 & -0.45 & $233.00 *$ & 0.49 \\
\hline Total & 27 & 0.19 & 19 & -0.41 & $160.00 *$ & 0.67 \\
\hline \multicolumn{7}{|l|}{ Episodic memory } \\
\hline Immediate recall (words) & 29 & -0.19 & 24 & -0.44 & 292.50 & - \\
\hline Late recall (words) & 29 & 0.12 & 24 & -0.77 & 244.00 & - \\
\hline Immediate recall (pictures) & 29 & -0.60 & 24 & -0.89 & 301.50 & - \\
\hline Semantic memory & 29 & 0.28 & 24 & 0.25 & 254.50 & - \\
\hline Episodic-semantic memory - Total & 29 & -0.16 & 24 & -0.82 & 268.00 & - \\
\hline \multicolumn{7}{|l|}{ Oral language } \\
\hline Naming & 27 & 0.28 & 21 & 0.36 & 197.50 & - \\
\hline Phonological awareness (rhyme) & 28 & 0.44 & 24 & -0.11 & 264.00 & - \\
\hline Phonemic subtraction & 29 & 0.53 & 24 & 0.40 & 331.50 & - \\
\hline Phonological awareness - Total & 28 & 0.50 & 24 & 0.21 & 296.00 & - \\
\hline Comprehension & 29 & 0.31 & 24 & 0.29 & 294.00 & - \\
\hline Inferential processing & 29 & -0.47 & 24 & -1.32 & $231.50 *$ & 0.60 \\
\hline Total & 26 & $-0,42$ & 21 & -1.80 & $168.50 *$ & 0.69 \\
\hline \multicolumn{7}{|l|}{ Written language } \\
\hline Syllable reading & 29 & 0.28 & 23 & 0.17 & 288.00 & - \\
\hline Word reading & 29 & 0.29 & 24 & 0.16 & $238.50 *$ & 0.56 \\
\hline Pseudoword reading & 29 & 0.94 & 24 & 0.30 & 318.50 & - \\
\hline Reading - Total & 29 & 0.79 & 23 & -0.12 & 315.00 & - \\
\hline Comprehension & 29 & 0.17 & 24 & 0.00 & $238.50 *$ & 0.56 \\
\hline Words & 29 & -0.40 & 24 & -1.33 & 272.00 & - \\
\hline Pseudowords & 29 & 0.55 & 24 & -0.64 & 243.50 & - \\
\hline Words and pseudowords - Total & 29 & -0.59 & 24 & -1.35 & 261.50 & - \\
\hline Spontaneous writing & 29 & 0.33 & 24 & 0.40 & 336.00 & - \\
\hline Copied writing & 29 & 0.43 & 24 & 0.16 & $212.50 *$ & 0.71 \\
\hline Total & 29 & 0.29 & 23 & -0.96 & $233.00 *$ & 0.53 \\
\hline \multicolumn{7}{|l|}{ Executive functions } \\
\hline Semantic verbal fluency & 28 & 0.03 & 22 & -0.83 & $151.50 *$ & 0.96 \\
\hline Go/no go & 29 & 0.19 & 24 & 0.21 & 330.50 & - \\
\hline
\end{tabular}

$\mathrm{d}=$ Cohen's $\mathrm{d}$ (effect size); $\mathrm{n}=$ number of subjects; $\mathrm{U}=$ Mann-Whitney's $\mathrm{U}$ test.

$* \mathrm{p}<0.05 ; \mathrm{p}$-values corrected for multiple comparisons using Benjamini \& Hochberg's method. ${ }^{32}$ 
Table 3 - Group differences in neuropsychological subtest performance according to number of anxiety disorders

\begin{tabular}{|c|c|c|c|c|c|c|c|}
\hline Subtests & $\mathbf{n}$ & $\begin{array}{l}1 \mathrm{AD} \\
\text { (Md) }\end{array}$ & $\mathbf{n}$ & $\begin{array}{c}2 \text { or } 3 \text { AD } \\
\text { (Md) }\end{array}$ & $\mathbf{U}$ & $\mathbf{p}$ & d \\
\hline Episodic memory - Late recall (words) & 17 & 0.00 & 37 & -0.61 & 207.50 & $<0.05$ & 0.56 \\
\hline \multicolumn{8}{|l|}{ Oral language } \\
\hline Phonemic subtraction & 17 & 0.63 & 37 & 0.36 & 190.00 & $<0.05$ & 0.67 \\
\hline Phonological awareness - Total & 17 & 0.60 & 36 & -0.13 & 175.00 & $<0.05$ & 0.73 \\
\hline \multicolumn{8}{|l|}{ Written language } \\
\hline Syllable reading & 17 & 0.29 & 36 & 0.17 & 178.00 & $<0.05$ & 0.71 \\
\hline Word reading & 17 & 0.38 & 37 & 0.16 & 197.50 & $<0.05$ & 0.62 \\
\hline Comprehension & 17 & 0.33 & 37 & 0.01 & 172.50 & $<0.01$ & 0.77 \\
\hline
\end{tabular}

$A D=$ anxiety disorder; $d=$ Cohen's $d$ (effect size); $M d=$ median; $n=$ number of subjects; $U=$ Mann-Whitney's $U$ test.

P-values corrected for multiple comparisons using Benjamini \& Hochberg's method. ${ }^{32}$

\section{Discussion}

This study investigated the neuropsychological performance (attention, memory, language and executive functions) of children with anxiety disorders in comparison with a normative sample. Moreover, we evaluated neuropsychological performance according to symptom severity and presence of one vs. more diagnoses of anxiety disorders. Our results showed that children with more severe anxiety disorders presented impairment in memory (visuospatial working memory and semantic memory), semantic verbal fluency and oral and written language subtests when compared to less severe cases. Moreover, when children had two or three comorbid diagnoses of anxiety disorders, they performed worse in episodic memory (immediate recall), oral language (phonemic subtraction, phonological awareness) and written language (reading syllables and words, comprehension) compared to children with only one anxiety disorder diagnosis.

The association between a higher number of diagnoses of anxiety disorders and lower performance in visual working memory is in agreement with previous literature. ${ }^{9,13,18}$ Episodic and semantic memory were also affected in the present study: these cognitive abilities have not been consistently evaluated in pediatric anxiety research, although deficits in episodic memory were observed in adults with anxiety disorders. It was suggested that these deficits occur in the coding phase, as there is no improvement in performance when cues are used to recover memory. ${ }^{35}$ The present study suggests that this impairment may also occur in childhood, due to the influence of the presence of anxiety disorder.

The association between language aspects and anxiety in children has been demonstrated in some studies in the last decades. ${ }^{36,37}$ However, the direction of this relationship is still controversial. On the one hand, poorer academic performance may occur if students are distracted by their anxious thoughts (e.g., "I'm afraid I will fail"); children who report high rates of test anxiety performed poorly on classroom tests. ${ }^{38}$ Alternatively, it is possible that children with significant reading disabilities may be more likely to develop anxiety symptoms in response to repeated failure experiences within the classroom. For example, children classified as poor versus good readers have been more likely to receive an anxiety disorder diagnosis in previous studies. ${ }^{39,40}$ Finally, we may state that both of these hypotheses are correct and that a bi-directional relation between anxiety and achievement exists. Negative affective states (e.g., anxiety) could develop in children who experience reading disabilities; and this emotional distress could, in turn, result in continued difficulty learning. ${ }^{41}$

Deficits in verbal fluency and phonemic verbal fluency have been implicated in anxiety disorders in other studies. 6,7 Here, we extend previous studies by showing that these deficits are also present in semantic verbal fluency and are also related to the severity of anxiety symptoms in children with a diagnosis of anxiety disorder. Verbal fluency is widely considered a measure of executive functioning. ${ }^{42,43}$ Other studies also show a dose-response relationship between anxiety severity and other measures of executive function, such as conflict scores in the attention network. ${ }^{8,44,45}$ These findings raised questions on whether those deficits are specific to anxiety disorders, or if they are related to the "p-factor", i.e., the overall severity of psychopathology across disorders, shared between both internalizing and externalizing disorders, as suggested by the referred studies. 
Our study has some limitations. First, it suggests that childhood anxiety disorders are associated with impairments in memory and language domains in some children (between 5 and 44\% in this sample depending on the neuropsychological function assessed). However, we cannot rule out the possibility of difficulties in other domains, since NEUPSILIN-Inf evaluates a few aspects of attention and executive functions. Thus, future studies should investigate different aspects/ components (e.g., planning, cognitive flexibility, speed of processing) of these neuropsychological functions in children with a primary anxiety diagnosis. Second, neuropsychological profiles according to the different types of anxiety disorder (e.g., generalized anxiety, social phobia) should be further investigated in order to clarify neurocognitive mechanisms of specific anxiety diagnoses in childhood. Third, our small sample size prevents us from detecting subtle differences between the groups. Therefore, studies with larger sample sizes are still needed to understand the neuropsychological underpinnings of anxiety disorders in children.

\section{Conclusions}

The present study reinforces previous findings that cognitive functions (e.g., memory and language) might be compromised in anxiety disorders in children, even in situations where there is no emotional context (e.g.., threat). ${ }^{6,12}$ Interventions targeting cognitive mechanisms at early age may be studied to minimize future problems related to anxiety disorders.

\section{Acknowledgements}

This research was supported by Fundo de Incentivo à Pesquisa - Hospital de Clínicas de Porto Alegre (FIPEHCPA).

Gisele Gus Manfro is a senior researcher scholarship recipient from Conselho Nacional de Desenvolvimento Científico e Tecnológico (CNPq).

\section{Disclosure}

No conflicts of interest declared concerning the publication of this article.

\section{References}

1. Paula CS, Coutinho ES, Mari JJ, Rohde LA, Miguel EC, Bordin IA. Prevalence of psychiatric disorders among children and adolescents from four Brazilian regions. Braz J Psychiatry. 2015;37:178-9.

2. Beesdo K, Knappe S, Pine DS. Anxiety and anxiety disorders in children and adolescents: developmental issues and implications for DSM-V. Psychiatr Clin North Am. 2009;32:483-524.

3. Murphy YE, Luke A, Brennan E, Francazio S, Christopher I, Flessner CA. An investigation of executive functioning in pediatric anxiety. Behav Modif. 2018;42:885-913.

4. Susa-Erdogan G, Bengà O, Mone I, Miclea M. The impact of childhood anxiety on processes of attentional executive control in the presence of emotional face distractors. J Exp Psychopathol. 2016;7:404-22.

5. Petersen SE, Posner MI. The attention system of the human brain: 20 years after. Annu Rev Neurosci. 2012;35:73-89.

6. Toazza R, Salum GA, Flores SM, Jarros RB, Pine DS, de Salles JF, et al. Phonemic verbal fluency is associated with pediatric anxiety disorders: evidence from a community study. J Child Adolesc Psychopharmacol. 2014;24:149-57.

7. Toazza R, Salum GA, Jarros RB, DeSousa D, Salles JF, Manfro GG. Phonemic verbal fluency and severity of anxiety disorders in young children. Trends Psychiatry Psychother. 2016;38:100-4.

8. Mogg K, Salum GA, Bradley BP, Gadelha A, Pan P, Alvarenga $P$, et al. Attention network functioning in children with anxiety disorders, attention-deficit/hyperactivity disorder and non-clinical anxiety. Psychol Med. 2015;45:2633-46.

9. Aronen ET, Vuontela V, Steenari MR, Salmi J, Carlson S. Working memory, psychiatric symptoms, and academic performance at school. Neurobiol Learn Mem. 2005;83:33-42.

10. Staugaard SR. Threatening faces and social anxiety: a literature review. Clin Psychol Rev. 2010;30:669-90.

11. Toren $P$, Sadeh $M$, Wolmer L, Eldar S, Koren S, Weizman R, et al. Neurocognitive correlates of anxiety disorders in children: a preliminary report. J Anxiety Disord. 2000;14:239-47.

12. Jarros RB, Salum GA, Silva CTB, Toazza R, Becker N, Agranonik M, et al. Attention, memory, visuoconstructive, and executive task performance in adolescents with anxiety disorders: a case-control community study. Trends Psychiatry Psychother. 2017;39:5-11.

13. Vasa RA, Roberson-Nay R, Klein RG, Mannuzza S, Moulton JL, Guardino $M$, et al. Memory deficits in children with and at risk for anxiety disorders. Depress Anxiety. 2007;24:85-94.

14. Hadwin JA, Brogan J, Stevenson J. State anxiety and working memory in children: a test of processing efficiency theory. Education Psychol. 2005;25:379-93.

15. Baddeley AD, Allen RJ, Hitch GJ. Binding in visual working memory: the role of the episodic buffer. Neuropsychologia. 2011;49:1393-400.

16. Baddeley A. Working memory: theories, models, and controversies. Annu Rev Psychol. 2012;63:1-29.

17. Baddeley AD, Hitch G. Working memory. In: Bower GH, editor. The psychology of learning and motivation: advances in research and theory. New York: Academic Press; 1974. p. 47-89.

18. Vance A, Ferrin M, Winther J, Gomez R. Examination of spatial working memory performance in children and adolescents with attention deficit hyperactivity disorder, combined type (ADHDCT) and anxiety. J Abnorm Child Psychol. 2013;41:891-900.

19. Owens M, Stevenson J, Norgate R, Hadwin JA. Processing efficiency theory in children: working memory as a mediator between trait anxiety and academic performance. Anxiety Stress Coping. 2008;21:417-30.

20. Günther T, Holtkamp K, Jolles J, Herpertz-Dahlmann B, Konrad $\mathrm{K}$. Verbal memory and aspects of attentional control in children and adolescents with anxiety disorders or depressive disorders. J Affec Disord. 2004;82:265-9.

21. Muris $P$, Mayer $B$, van Lint $C$, Hofman S. Attentional control and psychopathological symptoms in children. Pers Individ Differ. 2008;44:1495-505.

22. Salum GA, Petersen CS, Jarros RB, Toazza R, DeSousa D, Borba LN, et al. Group cognitive behavioral therapy and attention bias modification for childhood anxiety disorders: a factorial randomized trial of efficacy. J Child Adolesc Psychopharmacol. 2018;28:620-30.

23. Angelini AL, Alves IC, Custódio EM, Duarte WF, Duarte JL. Matrizes progressivas coloridas de Raven: escala especial. Manual. São Paulo: CETEPP; 1999.

24. Raven JC, Raven J, Court JH. Matrizes progressivas coloridas de Raven. Manual. Oxford: Oxford Psychologists Press; 1988.

25. Kaufman J, Birmaher B, Brent D, Rao U, Flynn C, Moreci P, et al. Schedule for Affective Disorders and Schizophrenia for SchoolAge Children-Present and Lifetime Version (K-SADS-PL): initial 
reliability and validity data. J Am Acad Child Adolesc Psiquiatry. 1997;36:980-8.

26. American Psychiatric Association. Diagnostic and statistical manual of mental disorders. 3rd ed. Washington: APA; 1980.

27. Brasil HHA. Development of the Brazilian version of K-SADS-

PL (Schedule for Affective Disorders and Schizophrenia for School Aged Children Present and Lifetime Version) and study of psychometric properties [thesis]. São Paulo: Universidade Federal de São Paulo; 2003.

28. The Pediatric Anxiety Rating Scale (PARS): development and psychometric properties. ] Am Acad Child Adolesc Psychiatry. 2002;41:1061-9.

29. Salles J, Sbicigo JB, Machado W, Miranda, MC, Fonseca, RP. Análise fatorial confirmatória do Instrumento de Avaliação Neuropsicológica Breve Infantil - NEUPSILIN-Inf. Psico-USF. 2014;19:119-30.

30. Salles JF, Fonseca RP, Cruz-Rodrigues C, Mello CB, Barbosa T, Miranda, MC. Development of the Child Brief Neuropsychological Assessment Battery NEUPSILIN-INF. Psico-USF. 2011;16:297305.

31. Salles, JF, Fonseca RP, Miranda MC, Berlin C, Rodrigues CC, Barbosa T. Instrumento de Avaliação Neuropsicológica Breve Infantil NEUPSILIN-Inf. São Paulo: Vetor; 2016.

32. Benjamini Y, Hochberg Y. Controlling the false discovery rate: a practical and powerful approach to multiple testing. J R Stat Soc B. $1995 ; 57: 289-300$.

33. Fritz CO, Morris PE, Richler JJ. Effect size estimates: current use, calculations, and interpretation. J Exp Psychol Gen. 2012;141:218.

34. Cohen J. Statistical power analysis for the behavioral sciences. 2nd ed. Hillsdale: Lawrence Earlbaum; 1988.

35. Airaksinen E, Larsson M, Forsell Y. Neuropsychological functions in anxiety disorders in population-based samples: evidence of episodic memory dysfunction. J Psychiatr Res. 2005;39:207-14.

36. Bryan T, Burstein K, Ergul C. The social-emotional side of learning disabilities: a science-based presentation of the state of the art. Learn Disabil Q. 2004;27:45-51.

37. Fincham FD, Hokoda A, Sanders R. Learned helplessness, test anxiety, and academic achievement: a longitudinal analysis. Child Dev. 1989;60:138-45.
38. Everson H, Smodlaka I, Tobias S. Exploring the relationship of test anxiety and metacognition on reading test performance: a cognitive analysis. Anxiety Stress Coping. 1994;7:85-96.

39. Carroll JM, Maughan B, Goodman R, Meltzer H. Literacy difficulties and psychiatric disorders: evidence for comorbidity. J Child Psychol Psychiatry. 2005;46:524-32.

40. Goldston DB, Walsh A, Arnold EM, Reboussin B, Daniel SS, Erkanli $A$, et al. Reading problems, psychiatric disorders, and functional impairment from mid- to late adolescence. J Am Acad Child Adolesc Psychiatry. 2007;46:25-32.

41. Yasutake D, Bryan T. The influence of affect on the achievement and behavior of students with learning disabilities. J Learn Disabil. 1995;28:329-34.

42. Chami S, MunroN, Docking K, McGregor K, Arciuli J, Baker E, et al. Changes in semantic fluency across childhood: normative data from Australian-English speakers. Int J Speech Lang Pathol. 2018;20:262-73.

43. Lezak MD, Howieson DB, Loring DW. Neuropsychological assessment. New York: Oxford University Press; 2004.

44. Caspi A, Houts RM, Belsky DW, Goldman-Mellor SJ, Harrington $\mathrm{H}$, Israel $\mathrm{S}$, et al. The $\mathrm{p}$ factor: one general psychopathology factor in the structure of psychiatric disorders? Clin Psychol Sci. 2014;2:119-37.

45. Martel MM, Pan PM, Hoffmann MS, Gadelha A, do Rosário MC, Mari $J$ J, et al. A general psychopathology factor ( $P$ factor) in children: structural model analysis and external validation through familial risk and child global executive function. J Abnorm Psychol. 2017;126:137-48.

\section{Correspondence:}

Juliana B. Sbicigo

Universidade Federal do Rio Grande do Sul (UFRGS)

Rua Ramiro Barcelos, 2600, Bairro Floresta

90035-003 - Porto Alegre, RS - Brazil

Tel.: +55 5133085341

E-mail: julianasbicigo@gmail.com 